\section{Patterns of sedentary behavior and compliance with public health recommendations in Spanish adolescents: the AFINOS study}

\author{
Patrones de sedentarismo y cumplimiento de las \\ recomendaciones de salud pública en adolescentes \\ españoles: estudio AFINOS
}

\author{
1 Departamento de \\ Metabolismo y Nutrición, \\ Instituto de Ciencia y \\ Tecnología de Alimentos y \\ Nutrición, Madrid, España. \\ 2 Facultad de Formación del \\ Profesorado y Educación, \\ Universidad Autónoma de \\ Madrid, Madrid, España. \\ ${ }^{3}$ Facultad de Medicina, \\ Universidad Complutense de \\ Madrid, Madrid, España. \\ Correspondence \\ D. M. Gómez \\ Grupo Immunonutrición, \\ Departamento de \\ Metabolismo y Nutrición, \\ Instituto de Ciencia y \\ Tecnología de Alimentos y \\ Nutrición. \\ Calle José Antonio Novais 10 \\ Madrid 28040, España. \\ d.martinez@uam.es
}

\begin{abstract}
The aims of the present study were: (i) describe patterns of sedentary behavior in Spanish adolescents; and (ii) determine the proportion of adolescents that do not meet the public health recommendations for sedentary behavior. This study comprised 1,724 Spanish adolescents (882 girls), aged 13 to 16 years. Patterns of sedentary behavior (TV viewing, use of computer games, console games and surfing the Internet) were assessed using the HELENA sedentary behavior questionnaire. The total proportion of adolescents watching TV, using computer and console games, and surfing the internet for more than two hours daily was $24 \%, 9 \%$, $7 \%$, and $17 \%$, respectively, on weekdays, and 50\%, 22\%, 16\%, and $35 \%$, respectively, on weekends. Over $63 \%$ of the adolescents from the study did not meet the recommendation for sedentary behavior $(<2$ hours daily screen time) on weekdays and $87 \%$ did not comply with this recommendation on weekends. Since sedentary behavior plays a key role in adolescent health, public health interventions in Spain that take these factors into consideration are needed.
\end{abstract}

Sedentary Lifestyle; Adolescent; Health Public Policy
David Martínez Gómez 1,2

Oscar L. Veiga 2

Belén Zapatera 1

Verónica Cabanas-Sánchez 2

Sonia Gomez-Martinez 1

David Martinez-Hernández 3

Ascensión Marcos 1

\section{Introduction}

In today's postmodern society, most people spend the majority of their waking hours engaging in sedentary behavior 1. Emerging evidence shows that prolonged sedentary behavior may have a deleterious effect on health 2 . For example, excessive sedentary behavior has been associated with premature all-cause and cardiovascular disease mortality, obesity and an unfavorable cardiometabolic risk factor profile in adults 2 . Regarding this behavior in youth, although evidence is more limited, excessive sedentary behavior appears to have a harmful effect on health 3,4 . Consequently, educational and public health organizations have focused efforts on promoting a decrease in sedentary behavior from an early age 5 .

Sedentary behavior includes activities that involve low levels of energy expenditure, consisting mainly of sitting time in different contexts 2 . Since several sedentary activities are part of young people's daily routine (e.g.: classes at school, studying), sedentary activities during leisure time are the target of preventive strategies 4 . Among youth, the most common leisure-time sedentary behavior is watching television (TV). Furthermore, new media technologies such as computers and games consoles have provided new opportunities for sedentary activity among this age group and while parents tend to limit the use of different kinds of media during child- 
hood, adolescents experience greater freedom, and availability of these activities is practically guaranteed 6 .

Surveillance studies in several countries have described sedentary behavior patterns in adolescents. However, when it comes to large samples of Spanish adolescents, data is limited to TV viewing behavior 9 and little is known about wider sedentary behavior among this age group in this country 7,8 . Likewise, the level of compliance with public health recommendations for sedentary behavior is practically unknown ${ }^{8}$. From a public health perspective, this study has the following two-fold aim: (i) describe patterns of sedentary behavior in Spanish adolescents; and (ii) determine the proportion of adolescents that do not meet public health recommendations for sedentary behavior.

\section{Methods}

\section{Study design and sampling}

Participants for the current study were recruited from the AFINOS (La Actividad Física como Agente Preventivo del Desarrollo de Sobrepeso, Obesidad, Alergias, Infecciones y Factores de Riesgo Cardiovascular en Adolescentes - Physical Activity as a Preventive Measures Against the Development of Overweight, Obesity, Infections, Allergies and Cardiovascular Risk Factors in Adolescents) study. The AFINOS study rationale and methods have been presented in detail elsewhere 10. In brief, the AFINOS study is a survey performed between 2007 and 2008 that aimed to evaluate lifestyle and health indicators by conducting a questionnaire with a representative sample of adolescents $(\mathrm{N} \approx 2000)$ aged 13 to 16 years from 12 secondary schools (eight to eleventh grades) in the region of Madrid, Spain. Based on the geographic distribution of adolescents in the Madrid region, $46 \%$ of the sample was selected from Madrid city, 35\% from the city's suburbs and 19\% from the region's villages. Random cluster sampling was used for sample collection where the first level of sampling was the entire set of secondary schools of the Madrid region and the second level was school class/ grade. An optional questionnaire regarding patterns of sedentary behavior was administered after an epidemiological questionnaire. A total of 1,999 adolescents (910 girls) completed this questionnaire. After the exclusion of 200 adolescents (111 girls) aged 17 years, this study uses valid data regarding the patterns of sedentary behavior obtained from a sample comprising 842 boys and 882 girls $(n=1,724)$.
Human subject approval was obtained from the Ethics Committee of the Puerta de Hierro Hospital (Madrid) and the Bioethics Committee of the Spanish National Research Council (CSIC). All participating parents or guardians and adolescents gave their written informed consent.

\section{Patterns of sedentary behavior}

Patterns of sedentary behavior were assessed using the HELENA (Healthy Lifestyle in Europe by Nutrition in Adolescence) sedentary behavior questionnaire 6 . This questionnaire, designed ad hoc within the HELENA study framework, was used to assess sedentary activities practiced by European adolescents from nine countries (Greece, Germany, Belgium, France, Hungary, Italy, Sweden, Austria and Spain). For a typical weekday and weekend day adolescents reported the number of hours spent on different sedentary pursuits using a seven-point Likert scale ( $1=$ no time; $2=$ less than $1 / 2$ hour; $3=1 / 2-1$ hour; $4=1-2$ hours; $5=2-3$ hours; $6=3-4$ hours and; $7=$ more than 4 hours). The leisure-time sedentary activities selected for this study were: TV viewing, computer games, console games and surfing the internet. This questionnaire displayed moderate seven-day test-retest reliability (intraclass correlation coefficients ranging from 0.36 to 0.77 , and 0.71 to 0.78 for weekdays and weekends, respectively) when assessing these four sedentary activities in a sub-sample of 183 adolescents aged 13 to 18 years from the HELENA study 5 . Overall screen time was computed by summing the time spent on the four sedentary activities. In addition, adolescents also reported the presence (yes/no) of a television in their bedroom.

\section{Public health recommendations for sedentary behavior}

Four public health recommendations launched by the American Academy of Pediatrics (AAP; http://www.aap.org) and the U.S. Department of Health and Human Services (USDHHS; http:// www.hhs.gov) were selected for this study. We included the APP recommendations because they are well-known and supported worldwide, and the new USDHHS recommendations because they include a distinction between two types of sedentary activities. The AAP recommends: (i) the removal of TV sets from adolescents' bedrooms; and (ii) that adolescents should not spend more than two hours a day on screen-based activities (e.g., TV viewing, computer games, console games, etc.) ${ }^{5}$. The USDHHS Healthy People 2020 objectives (http://www.healthypeople.gov) propose: (i) an increase in the proportion of ado- 
lescents viewing TV/videos or playing console games for no more than two hours a day; and (ii) an increase in the proportion of adolescents that use a computer or play computer games (for non-school activities) for no more than two hours a day.

\section{Statistical analysis}

The proportion (\%) of adolescents who spend more than two hours on each sedentary activity (TV viewing, computer games, console game and surfing the internet) was calculated separately for week and weekend days and stratified according to gender and age group (13 to 14 years and 15 to 16 years). The proportion (\%) of adolescents who did not meet the AAP and USDHHS recommendations was also calculated for the total sample and stratified by gender and age. Pearson chisquare tests were used to compare proportions by gender, age and day (weekday $v s$. weekend). All statistical analyses were run on PASW (Predictive Analytics SoftWare; SPSS Inc., Chicago, USA) for Macintosh. The level of statistical significance was set at $\mathrm{p}<0.05$.

\section{Results}

The proportion of adolescents watching TV, using the computer, playing console games and surfing the internet for more than two hours daily was $24 \%, 9 \%, 7 \%$ and $17 \%$, respectively, on weekdays, and $50 \%, 22 \%, 16 \%$ and $35 \%$, respectively, on weekends.

Patterns of sedentary behavior by age and sex are presented in Table 1. Although on weekends a significant main effect of age $(p=0.033)$ indicates differences between younger and older adolescent girls (younger $>$ older, $\mathrm{p}=0.004$ ), no differences were found between younger and older boys ( $p=0.932)$. A significant main effect of gender on electronic game and Internet use was found on both weekdays and weekends (all p < 0.05), with boys playing computer and console games more than girls and girls surfing the Internet more than boys. A significant main effect of age on surfing the Internet on weekdays and on weekends was found $(\mathrm{p}=0.041)$ showing that use is greater by older adolescents on weekdays in both sexes (younger $<$ older, $\mathrm{p}=0.002$ ) and on weekends in boys $(\mathrm{p}=0.879)$.

Forty-four percent of adolescents had a TV in their bedroom; this proportion was greater in

\begin{tabular}{|c|c|c|c|c|c|c|c|c|c|c|c|c|c|c|}
\hline & \multicolumn{6}{|c|}{ Adolescent boys } & \multicolumn{6}{|c|}{ Adolescent girls } & \multicolumn{2}{|c|}{ p-value } \\
\hline & n & All (\%) & $\mathrm{n}$ & $\begin{array}{c}13-14 \\
\text { years }(\%)\end{array}$ & $\mathrm{n}$ & $\begin{array}{c}15-16 \\
\text { years (\%) }\end{array}$ & $\mathrm{n}$ & All (\%) & n & $\begin{array}{c}13-14 \\
\text { years (\%) }\end{array}$ & $\mathbf{n}$ & $\begin{array}{c}15-16 \\
\text { years (\%) }\end{array}$ & Sex & Age \\
\hline $\begin{array}{l}\text { TV viewing }>2 \text { hours } \\
(N=1,675)\end{array}$ & 807 & & 388 & & 419 & & 868 & & 402 & & 466 & & & \\
\hline Weekdays & & 23.0 & & 20.4 & & 25.5 & & 24.4 & & 26.4 & & 22.7 & NS & NS \\
\hline Weekend * & & 49.1 & & 49.2 & & 48.9 & & 50.9 & & 56.2 & & 46.4 & NS & 0.033 \\
\hline $\begin{array}{l}\text { Computer games }>2 \\
\text { hours }(N=1,680)\end{array}$ & 812 & & 386 & & 426 & & 868 & & 400 & & 468 & & & \\
\hline Weekdays & & 11.1 & & 9.6 & & 12.4 & & 6.6 & & 7.2 & & 6.0 & 0.001 & NS \\
\hline Weekend * & & 26.6 & & 24.4 & & 28.6 & & 16.9 & & 18.8 & & 15.4 & $<0.001$ & NS \\
\hline $\begin{array}{l}\text { Console games }>2 \\
\text { hours }(N=1,678)\end{array}$ & 819 & & 393 & & 426 & & 859 & & 394 & & 465 & & & \\
\hline Weekdays & & 11.2 & & 11.2 & & 11.3 & & 2.2 & & 2.8 & & 1.7 & $<0.001$ & NS \\
\hline Weekend * & & 27.2 & & 29.0 & & 25.4 & & 4.4 & & 4.8 & & 4.1 & $<0.001$ & NS \\
\hline $\begin{array}{l}\text { Surfing the Internet }> \\
2 \text { hours }(N=1,663)\end{array}$ & 801 & & 381 & & 420 & & 862 & & 399 & & 463 & & & \\
\hline Weekdays & & 14.5 & & 10.0 & & 18.6 & & 18.4 & & 16.5 & & 20.1 & 0.030 & 0.001 \\
\hline Weekend * & & 29.2 & & 23.9 & & 34.0 & & 39.3 & & 39.6 & & 39.1 & $<0.001$ & 0.041 \\
\hline
\end{tabular}

NS: not significant.

* $p<0.001$ denotes statistical significance between weekdays and weekends. 
boys than in girls (49\% compared to $38 \%$ ). Figure 1 shows the proportion of adolescents with a TV in their bedroom by gender and age. The chisquare test showed a significant effect of gender $(p<0.001)$ but not of age $(p=0.954)$ on the proportion of adolescents with TVs in their bedrooms. Table 2 presents the proportion of adolescents who do not meet the other public health recommendations for sedentary behavior by gender and age. A significant proportion of adolescents did not meet the AAP's screen time recommendation both on weekdays and on weekends (over $63 \%$ and $87 \%$, respectively). Non-compliance with this recommendation on weekdays was higher in boys and older adolescents, but age-specific differences were discarded on weekends.

The proportion of adolescents who exceed the USDHHS's recommendation for TV viewing and playing computer games was $34 \%$ on weekdays and $64 \%$ on weekends. Non compliance with this recommendation was higher in adolescent boys on both weekdays and weekends, and on weekends non compliance was greater in younger adolescents. The proportion of adolescents who exceeded USDHHS recommendations for computer and internet use was $30 \%$ on weekdays and $55 \%$ on weekends. There were no significant differences in compliance with this recommendation between genders on both weekdays and weekends, but non compliance was greater in older adolescents on weekdays.

\section{Discussion}

This study provides an insight into patterns of sedentary behavior in Spanish adolescents. Our results indicate that Spanish adolescents spent too much time watching TV. Moreover, time spent on sedentary activities is twice as high on weekends as on weekdays. In addition, boys spent more time using the computer and console games, while girls spent more time on the internet for non-study reasons. Finally, we found that most Spanish adolescents do not comply with public health recommendations for sedentary behavior.

The large amount of time spent watching TV is considered an important unhealthy behavior in adolescents due to its potential harmful effects linked to obesity 11, cardiometabolic risks 12,13 and other health behavior such as aggression, substance abuse, shortage of sleep, eating disorders and poor academic performance ${ }^{3,5}$. Therefore, the amount of time adolescents spend watching TV is considered a major public health problem and warrants monitoring. The present study found that $24 \%$ of adolescents spent more

Figure 1

Proportion of Spanish adolescents with a TV set in their bedroom $(N=1,724)$.

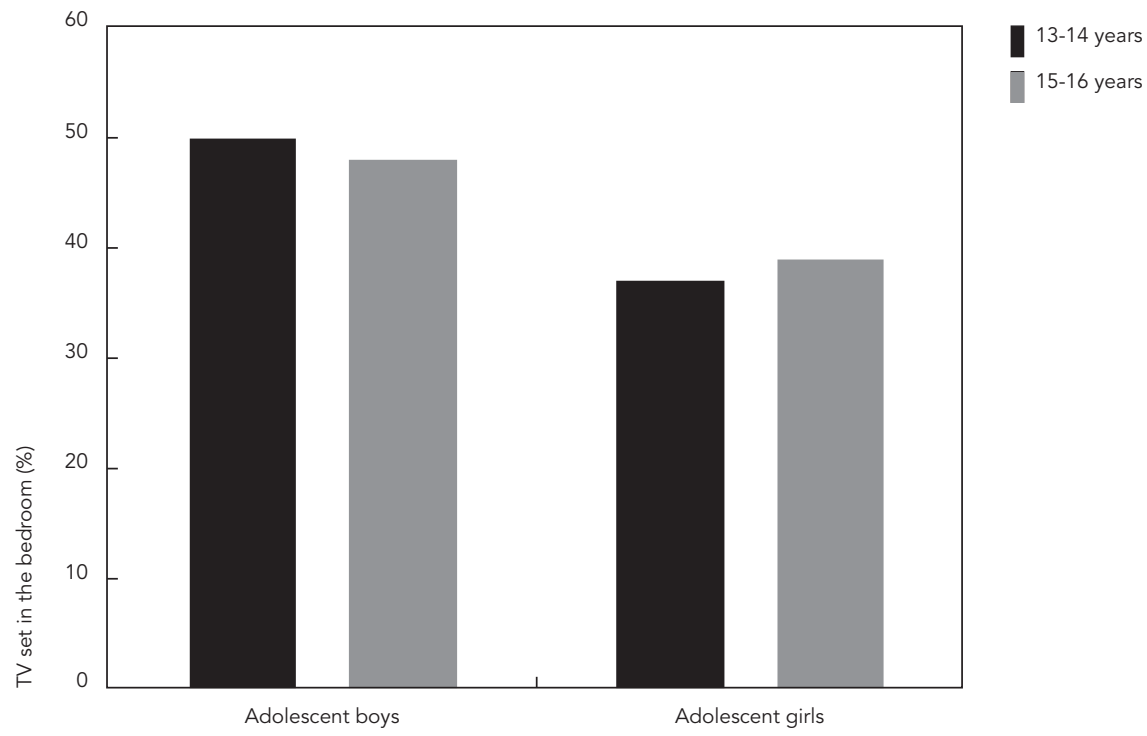


Proportion of Spanish adolescents not meeting public health recommendations for sedentary behavior.

\begin{tabular}{|c|c|c|c|c|c|c|c|c|c|c|c|c|c|c|}
\hline & \multicolumn{6}{|c|}{ Adolescent boys } & \multicolumn{6}{|c|}{ Adolescent girls } & \multicolumn{2}{|c|}{$\mathrm{p}$-value } \\
\hline & $\mathrm{n}$ & All (\%) & $\mathrm{n}$ & $\begin{array}{c}13-14 \\
\text { years (\%) }\end{array}$ & $\mathrm{n}$ & $\begin{array}{c}15-16 \\
\text { years }(\%)\end{array}$ & $\mathrm{n}$ & All (\%) & $\mathrm{n}$ & $\begin{array}{c}13-14 \\
\text { years (\%) }\end{array}$ & n & $\begin{array}{c}15-16 \\
\text { years (\%) }\end{array}$ & Sex & Age \\
\hline \multicolumn{15}{|l|}{ APA } \\
\hline $\begin{array}{l}\text { Screen time }>2 \text { hours } \\
(N=1,585)\end{array}$ & 762 & & 362 & & 400 & & 823 & & 378 & & 445 & & & \\
\hline Weekdays & & 66.0 & & 59.4 & & 72.0 & & 59.8 & & 59.3 & & 60.2 & 0.010 & 0.008 \\
\hline Weekend * & & 89.1 & & 89.8 & & 88.5 & & 85.4 & & 87.3 & & 83.8 & 0.028 & NS \\
\hline \multicolumn{15}{|l|}{ USDHHS Healthy People } \\
\hline $\begin{array}{l}\text { TV viewing/Console } \\
\text { games }>2 \text { hours } \\
(N=1,635)\end{array}$ & 791 & & 379 & & 412 & & 844 & & 389 & & 455 & & & \\
\hline Weekdays & & 40.1 & & 38.8 & & 41.3 & & 27.6 & & 30.3 & & 25.3 & $<0.001$ & NS \\
\hline Weekend * & & 70.7 & & 73.6 & & 68.0 & & 55.7 & & 62.7 & & 49.7 & $<0.001$ & $<0.001$ \\
\hline $\begin{array}{l}\text { Computer games/In- } \\
\text { ternet }>2 \text { hours } \\
(\mathrm{N}=1,636)\end{array}$ & 787 & & 373 & & 414 & & 849 & & 390 & & 459 & & & \\
\hline Weekdays & & 31.0 & & 25.2 & & 36.2 & & 28.2 & & 27.9 & & 28.3 & NS & 0.016 \\
\hline Weekend * & & 54.8 & & 50.9 & & 58.2 & & 55.7 & & 55.4 & & 56.0 & NS & NS \\
\hline
\end{tabular}

APA: American Academy of Pediatrics; NS: not significant; USDHHS: U.S. Department of Health and Human Services.

${ }^{*} p<0.001$ denotes statistical significance between weekdays and weekends.

than two hours a day watching TV on weekdays and $50 \%$ spent more than two hours a day watching TV on weekends. Comparisons with other countries are difficult due to differences in the methods used across studies, data presentation and year of data collection (e.g., continuous $v s$. categorical variables, the use of different cut-off points to categorize data such as $>3$ hours or $>$ 4 hours, data is often pooled for weekdays and weekends, etc.).

Overall, our findings show that Spanish adolescents spent less time watching TV than their counterparts in Brazil 14, Australia 15, Sweden 16, Italy 17 , United States 18,19, Scotland 20 and Canada 21 , but more time than Finish adolescents 22 . A comparison with recent results from the HELENA study of a relatively large pooled sample of European adolescents aged 12.5 to 17.5 years also suggests that Spanish adolescents may spend less time watching TV than other young Europeans 6 . This comparison is relevant since we used the same questionnaire and data collection also took place in 2007.

We did not find any difference between genders and time spent watching TV in our sample. Although results regarding the influence of age on time spent watching TV are contradictory, by contrast, almost all the aforementioned stud- ies showed that boys usually spend more time watching TV than girls 6,14,15,16,17,18,19,20,21,22. Results from the 2001-2002 Health Behavior in School-age Children (HBSC) survey of 11, 13 and 15-year-old schoolchildren show that in 26 of the 35 countries studied, boys spent significantly more time watching TV than girls 9 . It is interesting to note that there were no differences in TV viewing levels between boys and girls in the Spanish HBSC sample.

The time spent using electronic games was higher in boys and, the proportion of adolescents who played electronic games on weekends was between two and three times higher than on weekdays, which is similar to the results regarding time spent watching TV. Previous studies have also found gender-specific differences with regard to the amount of time spent by adolescents playing electronic games. For example, studies of Finish 22 and Australian 23 adolescents found that adolescent boys spent more time using electronic games than girls. A review by Marshall et al. 24 found that, on average, boys spent three times as long playing video games than girls. A study of Scottish adolescents by Biddle et al. 20 found that boys spent seven times more time playing computer and video games than girls. The same study 20 also found that adolescents spent 
twice as much time engaged in these activities on weekdays than on weekends. The HELENA study showed that European adolescent boys spent more time playing computer and video games than girls and time dedicated to these activities was greater on weekends 6 .

The negative health effects of playing electronic games (e.g., obesity) are still unclear 3,25. Indeed, there is some evidence that electronic games may be beneficial for youth (e.g., modeling of prosocial behaviors, improving cognitive performance and learning) 25 . Furthermore, compared with sedentary video games, several new active video games increase energy expenditure 26 and therefore a distinction should be made between active and inactive video games, since each game may have a different impact on health. Unfortunately, however, the current study did not distinguish between time spent on active and inactive electronic games.

The results of our study indicate that adolescent girls spend more time surfing the internet for non-study reasons than boys on both weekdays and weekends. Rey-López et al. ${ }^{6}$ also found that European adolescent girls surfed the internet more than boys on both weekdays and weekend days, but these results were mainly found in younger adolescents. The level of internet use for non-study reasons in previous studies is generally low. In some cases no differentiation was made between internet use for non-study and study reasons 27 and in general internet use is included in the category computer use 15,17,18,20,22,24.

The principal recommendations for sedentary behavior launched by the AAP in 2001 were also analyzed 5 . Our findings showed that around $44 \%$ of adolescents had a TV set in their bedroom. This figure is lower than in several previous findings for adolescents from Europe ${ }^{6}$, Italy ${ }^{17}$, United States 28,29 and France 30 . These results are important since having a TV in the bedroom is associated with more TV viewing time, less physical activity, poorer dietary habits, obesity and lower academic performance 29,30 and, therefore, removing the set from the bedroom is considered a practical method for decreasing the amount of time youth spend watching TV 31 .

The AAP's overall screen time recommendation is the most widely recognized recommendation on sedentary behavior 5 . Our results suggest an alarming $63 \%$ and $87 \%$ of adolescents did not meet the recommendation on week days and weekend days, respectively. Similar 6,18 or higher viewing levels were found by previous studies 32 . For example, data from the HELENA study showed that $33 \%$ of adolescents exceeded this limit based solely on TV viewing on weekdays, while $60 \%$ exceed the limit on weekends 6 . In a large sample of adolescents aged 12 to 15 years from the United States, Sisson et al. 18 found that $56 \%$ exceeded the AAP recommendation on a typical day. These figures raise key questions regarding public health, the suitability of this recommendation and the possibility of compliance among adolescents. As a result, studies have commonly used a recommendation of two hours or less as the main public recommendation for TV viewing 6,14,16,20,28.

The present study is the first to examine how many adolescents do not meet the recent USDHHS Healthy People 2020 recommendations for sedentary behavior. We found that over $30 \%$ of adolescents do not comply with the Healthy People 2020 recommendations during weekdays, and that this proportion almost doubles on weekends. The previous Healthy People 2010 recommendations suggested increasing the proportion of adolescents who viewed TV for two hours or less on a school day 33. According to data resources from the Youth Risk Behavior Surveillance System and the Centers for Disease Control and Prevention, around $43 \%$ of adolescents in the United States do not comply with this recommendation 33 .

Limitations of the current study must be acknowledged. The AFINOS study only provides cross-sectional data and therefore longitudinal studies of sedentary behavior in Spanish adolescents are required in order to determine changes over time throughout adolescence. A longitudinal study by Nelson et al. 34 found no differences in TV viewing time and increases in leisure-time computer use throughout adolescence. In addition, the time spent on each sedentary activity was self-reported and these findings must therefore be interpreted with caution 35 .

In conclusion, the main results of this study may be summarized as follows: (i) TV viewing is the dominant sedentary pastime; (ii) time spent on sedentary activities on weekends was between two and three times greater than on weekdays; (iii) boys spent more time playing electronic games, whereas girls spent more time surfing the internet; (iv) $44 \%$ of adolescents had a TV set in their bedroom and most did not comply with other public health recommendations for sedentary behavior, particularly the AAP screen time recommendation. Since sedentary behavior plays a key role in adolescent health, these results should be taken into consideration when developing tailored public health interventions in Spain. 


\section{Resumen}

Los objetivos del estudio son: (i) describir los patrones de comportamiento sedentario en adolescentes españoles y (ii) establecer cuántos de ellos no cumplen las recomendaciones de salud pública sobre comportamiento sedentario. Participaron 1.724 adolescentes españoles (882 chicas) entre 13 y 16 años. Los patrones de comportamiento sedentario (ver la televisión, juegos de ordenador, videojuegos y navegar en Internet) fueron evaluados a través del cuestionario HELENA. La proporción total de adolescentes que ven la TV, usan juegos de ordenador o de consola y navegan en Internet durante $>2 \mathrm{~h}$ los dias de diario fue del $24 \%$, 9\%, 7\% y 17\%, respectivamente. Durante los fines de semana, la proporción fue del 50\%, 22\%, 16\% y 35\%. Más del 63\% del total de la muestra no cumplen las recomendaciones de tiempo sedentario total $<2$ horas durante los días de diario y el $87 \%$ no lo hace en días del fin de semana. Dado que las conductas sedentarias podrían ser relevantes en la salud de los adolescentes, las intervenciones de salud pública son necesarias en España.

Estilo de Vida Sedentario; Adolescente; Políticas Públicas de Salud

\section{References}

1. Owen N, Bauman A, Brown W. Too much sitting: a novel and important predictor of chronic disease risk? Br J Sports Med 2009; 43:81-3.

2. Owen N, Healy GN, Matthews CE, Dunstan DW. Too much sitting: the population health science of sedentary behavior. Exerc Sport Sci Rev 2010; 38:105-13.

3. Strasburger VC, Jordan AB, Donnerstein E. Health effects of media on children and adolescents. Pediatrics 2010; 125:756-67.

4. Ekelund U, Luan J, Sherar LB, Esliger DW, Griew P, Cooper A, et al. Moderate to vigorous physical activity and sedentary time and cardiometabolic risk factors in children and adolescents. JAMA 2012; 307:704-12.

\section{Contributors}

D. M. Gómez collected and interpreted data, carried out statistical analysis and drafted the manuscript. O. L. Veiga, S. Gomez-Martinez and A. Marcos contributed to overall study conception and design, collection and interpretation of data and the critical revision of the manuscript. B. Zapatera, V. Cabanas-Sánchez and D. Martinez-Hernández contributed to the collection and interpretation of data and critical revision of the manuscript. All authors approved the final version of this manuscript.

\section{Acknowledgments}

The authors would like to thank all participating adolescents and their families. This study was supported by the Spanish Ministry of Education and Science (DEP200656184-C03-02/PREV) and E.U. funding (FEDER). D. M. Gómez gratefully received a grant from the Spanish Ministry of Education and Science (AP2006-02464).
5. American Academy of Pediatrics, Committee on Public Education. American Academy of Pediatrics: children, adolescents, and television. Pediatrics 2001; 107:423-6.

6. Rey-López JP, Vicente-Rodriguez G, Ortega FB, Ruiz JR, Martinez-Gómez D, De Henauw S, et al. Sedentary patterns and media availability in $\mathrm{Eu}-$ ropean adolescents: the HELENA study. Prev Med 2010; 51:50-5.

7. Devís-Devís J, Peiró-Velert C, Beltrán-Carrillo VJ, Tomás JM. Screen media time usage of 12-16 yearold Spanish school adolescents: effects of personal and socioeconomic factors, season and type of day. J Adolesc 2009; 32:213-31. 
8. Hoyos-Cillero I, Jago R, Sebire S. Individual and social predictors of screen-viewing among Spanish school children. Eur J Pediatr 2011; 170:93-102.

9. Vereecken CA, Todd J, Roberts C, Mulvihill C, Maes L. Television viewing behaviour and associations with food habits in different countries. Public Health Nutr 2006; 9:244-50.

10. Veiga OL, Gómez-Martínez S, Martínez-Gómez D, Villagra A, Calle ME, Marcos A. Physical activity as a preventive measure against overweight, obesity, infections, allergies and cardiovascular disease risk factors in adolescents: AFINOS study protocol. BMC Public Health 2009; 9:475.

11. Vicente-Rodríguez G, Rey-López JP, Martín-Matillas M, Moreno LA, Wärnberg J, Redondo C, et al. Television watching, videogames, and excess of body fat in Spanish adolescents: the AVENA study. Nutrition 2008; 24:654-62.

12. Martínez-Gómez D, Eisenmann JC, Gómez-Martínez S, Veses A, Marcos A, Veiga OL. Sedentary behavior, adiposity and cardiovascular risk factors in adolescents: the AFINOS study. Rev Esp Cardiol 2010; 63:277-85.

13. Martínez-Gómez D, Rey-López JP, Chillón P, Gómez-Martínez S, Vicente-Rodríguez G, MartínMatillas M, et al. Excessive TV viewing and cardiovascular disease risk factors in adolescents: the AVENA cross-sectional study. BMC Public Health 2010; 10:274.

14. Wells JC, Hallal PC, Reichert FF, Menezes AM, Araújo CL, Victora CG. Sleep patterns and television viewing in relation to obesity and blood pressure: evidence from an adolescent Brazilian birth cohort. Int J Obes (Lond) 2008; 32:1042-9.

15. Scully M, Dixon H, White V, Beckmann K. Dietary, physical activity and sedentary behaviour among Australian secondary students in 2005. Health Promot Int 2007; 22:236-45.

16. Ortega FB, Ruiz JR, Sjöström M. Physical activity, overweight and central adiposity in Swedish children and adolescents: the European Youth Heart Study. Int J Behav Nutr Phys Act 2007; 4:61.

17. Patriarca A, Di Giuseppe G, Albano L, Marinelli $\mathrm{P}$, Angelillo IF. Use of television, videogames, and computer among children and adolescents in Italy. BMC Public Health 2009; 9:139.

18. Sisson SB, Church TS, Martin CK, Tudor-Locke C, Smith SR, Bouchard C, et al. Profiles of sedentary behavior in children and adolescents: the U.S. National Health and Nutrition Examination Survey, 2001-2006. Int J Pediatr Obes 2009; 4:353-9.

19. Eisenmann JC, Bartee RT, Wang MQ. Physical activity, TV viewing, and weight in U.S. youth: 1999 Youth Risk Behavior Survey. Obes Res 2002; 10 : 379-85.

20. Biddle SJ, Gorely T, Marshall SJ, Cameron N. The prevalence of sedentary behavior and physical activity in leisure time: a study of Scottish adolescents using ecological momentary assessment. Prev Med 2009; 48:151-5.
21. Kautiainen S, Koivusilta L, Lintonen T, Virtanen SM, Rimpelä A. Use of information and communication technology and prevalence of overweight and obesity among adolescents. Int J Obes (Lond) 2005; 29:925-33.

22. Mark AE, Boyce WF, Janssen I. Television viewing, computer use and total screen time in Canadian youth. Paediatr Child Health 2006; 11:595-9.

23. Olds T, Wake M, Patton G, Ridley K, Waters E, Williams J, et al. How do school-day activity patterns differ with age and gender across adolescence? J Adolesc Health 2009; 44:64-72.

24. Marshall SJ, Gorely T, Biddle SJ. A descriptive epidemiology of screen-based media use in youth: a review and critique. J Adolesc 2006; 29:333-49.

25. Swinburn B, Shelly A. Effects of TV time and other sedentary pursuits. Int J Obes (Lond) 2008; 32 Suppl 7:S132-6.

26. Biddiss E, Irwin J. Active video games to promote physical activity in children and youth: a systematic review. Arch Pediatr Adolesc Med 2010; 164: 664-72.

27. Van den Bulck J. Television viewing, computer game playing, and Internet use and self-reported time to bed and time out of bed in secondaryschool children. Sleep 2004; 27:101-4.

28. Springer AE, Kelder SH, Barroso CS, Drenner KL, Shegog R, Ranjit N, et al. Parental influences on television watching among children living on the Texas-Mexico border. Prev Med 2010; 51:112-7.

29. Barr-Anderson DJ, van den Berg P, Neumark-Sztainer D, Story M. Characteristics associated with older adolescents who have a television in their bedrooms. Pediatrics 2008; 121:718-24.

30. Delmas C, Platat C, Schweitzer B, Wagner A, Oujaa M, Simon C. Association between television in bedroom and adiposity throughout adolescence. Obesity (Silver Spring) 2007; 15:2495-503.

31. Escobar-Chaves SL, Markham CM, Addy RC, Greisinger A, Murray NG, Brehm B. The Fun Families Study: intervention to reduce children's TV viewing. Obesity (Silver Spring) 2010; 18 Suppl 1: S99-101.

32. Mark AE, Janssen I. Relationship between screen time and metabolic syndrome in adolescents. J Public Health (Oxf) 2008; 30:153-60.

33. U.S. Department of Health and Human Services. Healthy People 2010: with understanding and improving health and objectives for improving health. Washington DC: U.S. Government Printing Office; 2000

34. Nelson MC, Neumark-Stzainer D, Hannan PJ, Sirard JR, Story M. Longitudinal and secular trends in physical activity and sedentary behavior during adolescence. Pediatrics 2006; 118:e1627-34.

35. Bryant MJ, Lucove JC, Evenson KR, Marshall S. Measurement of television viewing in children and adolescents: a systematic review. Obes Rev 2007; 8:197-209.

Submitted on 23/Jan/2012

Final version resubmitted on $05 / \mathrm{Jul} / 2012$

Approved on 17/Aug/2012 